\title{
A highly conserved cryptic epitope in the receptor-binding domains of SARS-CoV-2 and SARS-CoV
}

\author{
Meng Yuan', Nicholas C. Wu'*, Xueyong Zhu', Chang-Chun D. Lee', Ray T. Y. So ${ }^{1}$, Huibin Lv', \\ Chris K. P. Mok ${ }^{2} \uparrow$, Ian A. Wilson ${ }^{1,3} \uparrow$ \\ ${ }^{1}$ Department of Integrative Structural and Computational Biology, The Scripps Research Institute, La Jolla, CA 92037, USA. ${ }^{2 H K U-P a s t e u r ~ R e s e a r c h ~ P o l e, ~ S c h o o l ~ o f ~ P u b l i c ~}$ \\ Health, Li Ka Shing Faculty of Medicine, The University of Hong Kong, Hong Kong SAR, China. ${ }^{3}$ The Skaggs Institute for Chemical Biology, The Scripps Research Institute, La \\ Jolla, CA, 92037, USA. \\ *These authors contributed equally to this work.
}

†Corresponding author. Email: ch02mkp@hku.hk (C.K.P.M.); wilson@scripps.edu (I.A.W.)

The outbreak of COVID-19 caused by SARS-CoV-2 virus has now become a pandemic, but there is currently very little understanding of the antigenicity of the virus. We therefore determined the crystal structure of CR3022, a neutralizing antibody previously isolated from a convalescent SARS patient, in complex with the receptor-binding domain (RBD) of the SARS-CoV-2 spike (S) protein to $3.1 \AA$. CR3022 targets a highly conserved epitope, distal from the receptor-binding site, that enables cross-reactive binding between SARS-CoV-2 and SARS-CoV. Structural modeling further demonstrates that the binding epitope can only be accessed by CR3022 when at least two RBD on the trimeric S protein are in the "up" conformation and slightly rotated. Overall, this study provides molecular insights into antibody recognition of SARS-CoV-2.

The ongoing outbreak of Coronavirus Disease 2019 (COVID19) originally emerged in China during December 2019 (1) and had become a global pandemic by March 2020. COVID19 is caused by a novel coronavirus, severe acute respiratory syndrome coronavirus 2 (SARS-CoV-2) (2). Two other coronaviruses have caused world-wide outbreaks in the past two decades, namely SARS-CoV (2002-2003) and Middle East respiratory syndrome coronavirus (MERS-CoV) (2012-present). The surface spike glycoprotein (S), which is critical for virus entry through engaging the host receptor and mediating virus-host membrane fusion, is the major antigen of coronaviruses. The S proteins of SARS-CoV-2 and SARS-CoV, which are phylogenetically closely related, have an amino-acid sequence identity of around $77 \%$ (3). Such a high degree of sequence similarity raises the possibility that cross-reactive epitopes may exist.

CR3022, which was previously isolated from a convalescent SARS patient, is a neutralizing antibody that targets the receptor-binding domain (RBD) of SARS-CoV (4). The immunoglobulin heavy chain variable, diversity, and joining (IGHV, IGHD, and IGHJ) regions are encoded by germline genes IGHV5-51, IGHD3-10, and IGHJ6, while the light chain variable and joining regions are encoded by IGKV4-1 and IGKJ2 (4). Based on IgBlast analysis (5), the IGHV of CR3022 is $3.1 \%$ somatically mutated at the nucleotide sequence level, which results in eight amino-acid changes from the germline sequence, whereas IGKV of CR3022 is $1.3 \%$ somatically mutated resulting in three amino-acid changes from the germline sequence (fig. S1). A recent study has shown that
CR3022 can also bind to the RBD of SARS-CoV-2 (6). This finding provides an opportunity to uncover a cross-reactive epitope. We therefore determined the crystal structure of CR3022 with the SARS-CoV-2 RBD (Fig. 1A) at $3.1 \AA$ resolution (table S1 and fig. S2, A and B) (7). CR3022 uses both heavy and light chains (Fig. 1B), and all six complementaritydetermining region (CDR) loops (Fig. 1C) for interaction with the RBD. The buried surface area on the epitope is $917 \AA^{2}$ and SARS-CoV-2 recognition by CR3022 is largely driven by hydrophobic interactions (Fig. 1E). Five out of 11 somatic mutations are found in the paratope region (defined as residues on the antibody buried by RBD) (fig. S2C), implying their likely importance in the affinity maturation process.

Out of 28 residues in the epitope (defined as residues buried by CR3022), 24 (86\%) are conserved between SARS-CoV2 and SARS-CoV (Figs. 1D and 2A). This high sequence conservation explains the cross-reactivity of CR3022. Nonetheless, despite having a high conservation of the epitope residues, CR3022 Fab binds to SARS-CoV RBD $\left(K_{d}=1 \mathrm{nM}\right)$ with a much higher affinity than to SARS-CoV-2 RBD $\left(\mathrm{K}_{\mathrm{d}}=\right.$ $115 \mathrm{nM}$ ) (Table 1 and fig. S3). The difference in binding affinity of CR3022 between SARS-CoV-2 and SARS-CoV RBDs is likely due to the non-conserved residues in the epitope (Fig. 2). The most dramatic difference is an additional N-glycosylation site at N370 on SARS-CoV (N357 in SARS-CoV numbering). The N-glycan sequon (NxS/T) arises from an amino-acid difference at residue 372 , where SARS-CoV has a Thr compared to Ala in SARS-CoV-2 (Fig. 2B). Mass spectrometry analysis shows that a complex glycan is indeed present at this 
N-glycosylation site in SARS-CoV (8). An N-glycan at N370 would fit into a groove formed between heavy and light chains (Fig. 2C), which could increase contact and, hence, binding affinity to CR3022. This result also suggests that the difference in antigenicity between the RBDs of SARS-CoV-2 and SARS-CoV can at least be partially attributed to the Nglycosylation site at residue 370. We tested whether CR3022 was able to neutralize SARS-CoV-2 and SARS-CoV in an in vitro microneutralization assay (7). While CR3022 could neutralize SARS-CoV, it did not neutralize SARS-CoV-2 at the highest concentration tested $(400 \mu \mathrm{g} / \mathrm{mL})$ (fig. S4). This in vitro neutralization result is consistent with lower affinity binding of CR3022 for SARS-CoV-2, although other explanations are possible as outlined below.

SARS-CoV-2 uses the same host receptor, angiotensin I converting enzyme 2 (ACE2) as SARS-CoV (3, 9-11). Interestingly, the epitope of CR3022 does not overlap with the ACE2binding site (Fig. 3A). Structural alignment of the CR3022SARS-CoV-2 RBD complex with the ACE2-SARS-CoV-2 RBD complex (11) further indicates that binding of CR3022 would not clash with ACE2 (12). This analysis implies that the neutralization mechanism of CR3022 for SARS-CoV does not depend on direct blocking of receptor binding, which is consistent with the observation that CR3022 does not compete with ACE2 for binding to the RBD (6). Unlike CR3022, most known SARS RBD-targeted antibodies compete with ACE2 for binding to RBD (4, 13-16). The epitopes of these antibodies are very different from that of CR3022 (Fig. 3B). In fact, it has been shown that CR3022 can synergize with other RBD-targeted antibodies to neutralize SARS-CoV (4). Although CR3022 itself cannot neutralize SARS-CoV-2 in this in vitro assay, whether CR3022 can synergize with other SARSCoV-2 RBD-targeted monoclonal antibodies for neutralization remains to be determined.

The recently determined cryo-EM structure of homotrimeric SARS-CoV-2 S protein $(17,18)$ demonstrated that the $\mathrm{RBD}$, as in other coronaviruses $(19,20)$ can undergo a hingelike movement to transition between "up" or "down" conformations (Fig. 4A). ACE2 host receptor can only interact with the RBD when it is in the "up" conformation, whereas the "down" conformation is inaccessible to ACE2. Interestingly, the epitope of CR3022 is also only accessible when the RBD is in the "up" conformation (Fig. 4, B and C). However, even when one RBD in the SARS-CoV-2 S protein is in the "up" conformation, the binding of CR3022 to RBD can still be sterically hindered. Structural alignment of CR3022-SARS-CoV2 RBD complex with the SARS-CoV-2 S protein $(17,18)$ indicates that CR3022 variable region would clash with the RBD on the adjacent protomer if the latter adopted a "down" conformation. In addition, CR3022 variable domain would clash with the S2 underneath the RBD, and CR3022 constant region would clash with the N-terminal domain (Fig. 4D).
Although as compared to SARS-CoV-2, the "up" conformation of the RBD in SARS-CoV has a larger dihedral angle to the horizontal plane of the S protein (fig. S5), the same clashes described above would exist in SARS-CoV S protein (fig. S6).

In order for CR3022 to bind to the $\mathrm{S}$ protein, clashes described above need to be resolved. The clash with the CR3022 variable domain can be partially relieved when the targeted RBD on one protomer of the trimer and the RBD on the adjacent protomer are both in the "up" conformation (Fig. 4E). Of note, SARS-CoV S protein with two RBDs in the "up" conformation has been observed in cryo-EM studies $(19,21,22)$. Nevertheless, clashes to N-terminal domain (NTD) and S2 would still exist in the two-"up" configuration. Further structural modeling shows that all clashes can be avoided with a slight rotation of the targeted-RBD in the double-"up" configuration (Fig. 4F). This conformational change is likely to be physiological relevant since CR3022 can neutralize SARSCoV. In addition, our ELISA experiment demonstrated that CR3022 is able to interact with the SARS-CoV-2 virus. While the binding signals of CR3022 and m396, which is a SARSCoV-specific antibody (Fig. 4G, left panel) $(6,17)$ to SARS-CoV virus were comparable in ELISA (p-value $>0.05$, two-tailed $t$ test), CR3022 had a significantly higher binding signal compared to m396 to the SARS-CoV-2 virus (p-value $=0.003$, twotailed $t$ test) (Fig. 4G, right panel), although less than to SARS $\mathrm{CoV}$, consistent with their relative binding to the RBD (Table 1 and fig. S3).

Overall, our study provides insight into how SARS-CoV-2 can be targeted by the humoral immune response and revealed a conserved, but cryptic epitope shared between SARSCoV-2 and SARS-CoV. Recently, our group and others have identified a conserved epitope on influenza A virus hemagglutinin (HA) that is located in the trimeric interface and is only exposed through protein "breathing" (23-25), which is somewhat analogous to the epitope of CR3022. Antibodies to this influenza HA trimeric interface epitope do not exhibit in vitro neutralization activity but can confer in vivo protection. Similarly, antibodies to another conserved epitope that partially overlaps with the influenza HA trimeric interface also are non-neutralizing in vitro, but protective in vivo (26). Examples of antibodies that do not have in vitro neutralization activity but confer in vivo protection, have also been reported for influenza virus (27), herpesvirus (28), cytomegalovirus (29), alphavirus (30), and dengue virus (31). Therefore, although CR3022 does not neutralize SARS-CoV-2 in vitro, it is possible that this epitope can confer in vivo protection. Further studies will require suitable animal models, which have yet to be established.

As this coronavirus outbreak continues to pose an enormous global risk $(32,33)$, the availability of conserved epitopes may allow structure-based design not only of a SARS-CoV-2 vaccine, but also for cross-protective antibody 
responses against future coronavirus epidemics and pandemics. While a more universal coronavirus vaccine is not the most urgent goal at present, it is certainly worthwhile for future consideration especially as cross-protective epitopes are identified so that we can be better prepared for the next novel coronavirus outbreak.

\section{REFERENCES AND NOTES}

1. C. Huang, Y. Wang, X. Li, L. Ren, J. Zhao, Y. Hu, L. Zhang, G. Fan, J. Xu, X. Gu, Z. Cheng, T. Yu, J. Xia, Y. Wei, W. Wu, X. Xie, W. Yin, H. Li, M. Liu, Y. Xiao, H. Gao, L. Guo, J. Xie, G. Wang, R. Jiang, Z. Gao, Q. Jin, J. Wang, B. Cao, Clinical features of patients infected with 2019 novel coronavirus in Wuhan, China. Lancet 395, 497506 (2020). doi:10.1016/S0140-6736(20)30183-5 Medline

2. Coronaviridae Study Group of the International Committee on Taxonomy of Viruses, The species Severe acute respiratory syndrome-related coronavirus: Classifying 2019-nCoV and naming it SARS-CoV-2. Nat. Microbiol. 5, 536-544 (2020). doi:10.1038/s41564-020-0695-z Medline

3. P. Zhou, X.-L. Yang, X.-G. Wang, B. Hu, L. Zhang, W. Zhang, H.-R. Si, Y. Zhu, B. Li, C.L. Huang, H.-D. Chen, J. Chen, Y. Luo, H. Guo, R.-D. Jiang, M.-Q. Liu, Y. Chen, X.-R. Shen, X. Wang, X.-S. Zheng, K. Zhao, Q.-J. Chen, F. Deng, L.-L. Liu, B. Yan, F.-X. Zhan, Y.-Y. Wang, G.-F. Xiao, Z.-L. Shi, A pneumonia outbreak associated with a new coronavirus of probable bat origin. Nature 579, 270-273 (2020). doi:10.1038/s41586-020-2012-7 Medline

4. J. ter Meulen, E. N. van den Brink, L. L. M. Poon, W. E. Marissen, C. S. W. Leung, F. Cox, C. Y. Cheung, A. Q. Bakker, J. A. Bogaards, E. van Deventer, W. Preiser, H. W. Doerr, V. T. Chow, J. de Kruif, J. S. M. Peiris, J. Goudsmit, Human monoclonal antibody combination against SARS coronavirus: Synergy and coverage of escape mutants. PLOS Med. 3, e237 (2006). doi:10.1371/iournal.pmed.0030237 Medline

5. J. Ye, N. Ma, T. L. Madden, J. M. Ostell, IgBLAST: An immunoglobulin variable domain sequence analysis tool. Nucleic Acids Res. 41, W34-W40 (2013). doi:10.1093/nar/gkt382 Medline

6. X. Tian, C. Li, A. Huang, S. Xia, S. Lu, Z. Shi, L. Lu, S. Jiang, Z. Yang, Y. Wu, T. Ying, Potent binding of 2019 novel coronavirus spike protein by a SARS coronavirusspecific human monoclonal antibody. Emerg. Microbes Infect. 9, 382-385 (2020). doi:10.1080/22221751.2020.1729069 Medline

7. See supplementary materials.

8. Y. Watanabe, Z. T. Berndsen, J. Raghwani, G. E. Seabright, J. D. Allen, J. S. McLellan, I. A. Wilson, T. A. Bowden, A. B. Ward, M. Crispin, Vulnerabilities in coronavirus glycan shields despite extensive glycosylation. bioRxiv 2020.02.20.957472 [Preprint]. 21 February 2020. https://doi.org/10.1101/2020.02.20.957472.

9. M. Letko, A. Marzi, V. Munster, Functional assessment of cell entry and receptor usage for SARS-CoV-2 and other lineage B betacoronaviruses. Nat. Microbiol. 5 562-569 (2020). doi:10.1038/s41564-020-0688-y Medline

10. R. Yan, Y. Zhang, Y. Li, L. Xia, Y. Guo, Q. Zhou, Structural basis for the recognition of SARS-CoV-2 by full-length human ACE2. Science 367, 1444-1448 (2020). doi:10.1126/science.abb2762 Medline

11. J. Lan, J. Ge, J. Yu, S. Shan, H. Zhou, S. Fan, Q. Zhang, X. Shi, Q. Wang, L. Zhang, X. Wang, Crystal structure of the 2019-nCoV spike receptor-binding domain bound with the ACE2 receptor. bioRxiv 2020.02.19.956235 [Preprint]. 20 February 2020. https://doi.org/10.1101/2020.02.19.956235.

12. ACE2 also forms a dimer when it associates with an amino acid transporter BOAT1 (10). We modeled a CR3022 lgG onto this dimer structure and found no clashes of CR3022 with ACE2 in its dimeric form where the RBDs would likely come from adjacent trimers on the virus (10).

13. J. Sui, W. Li, A. Murakami, A. Tamin, L. J. Matthews, S. K. Wong, M. J. Moore, A. S. C. Tallarico, M. Olurinde, H. Choe, L. J. Anderson, W. J. Bellini, M. Farzan, W. A. Marasco, Potent neutralization of severe acute respiratory syndrome (SARS) coronavirus by a human $\mathrm{mAb}$ to $\mathrm{S} 1$ protein that blocks receptor association. Proc. Natl. Acad. Sci. U.S.A. 101, 2536-2541 (2004). doi:10.1073/pnas.0307140101 Medline

14. E. N. van den Brink, J. Ter Meulen, F. Cox, M. A. C. Jongeneelen, A. Thijsse, M. Throsby, W. E. Marissen, P. M. L. Rood, A. B. H. Bakker, H. R. Gelderblom, B. E.
Martina, A. D. M. E. Osterhaus, W. Preiser, H. W. Doerr, J. de Kruif, J. Goudsmit, Molecular and biological characterization of human monoclonal antibodies binding to the spike and nucleocapsid proteins of severe acute respiratory syndrome coronavirus. J. Virol. 79, 1635-1644 (2005). doi:10.1128/JVL.79.3.1635-1644.2005 Medline

15. J. D. Berry, S. Jones, M. A. Drebot, A. Andonov, M. Sabara, X. Y. Yuan, H. Weingartl, L. Fernando, P. Marszal, J. Gren, B. Nicolas, M. Andonova, F. Ranada, M. J. Gubbins, T. B. Ball, P. Kitching, Y. Li, A. Kabani, F. Plummer, Development and characterisation of neutralising monoclonal antibody to the SARS-coronavirus. J. Virol. Methods 120, 87-96 (2004). doi:10.1016/i.jviromet.2004.04.009 Medline

16. P. Prabakaran, J. Gan, Y. Feng, Z. Zhu, V. Choudhry, X. Xiao, X. Ji, D. S. Dimitrov, Structure of severe acute respiratory syndrome coronavirus receptor-binding domain complexed with neutralizing antibody. J. Biol. Chem. 281, 15829-15836 (2006). doi:10.1074/ibc.M600697200 Medline

17. D. Wrapp, N. Wang, K. S. Corbett, J. A. Goldsmith, C.-L. Hsieh, O. Abiona, B. S. Graham, J. S. McLellan, Cryo-EM structure of the 2019-nCoV spike in the prefusion conformation. Science 367, 1260-1263 (2020). doi:10.1126/science. abb2507 Medline

18. A. C. Walls, Y.-J. Park, M. A. Tortorici, A. Wall, A. T. McGuire, D. Veesler, Structure, function, and antigenicity of the SARS-CoV-2 spike glycoprotein. Cell S00928674(20)30262-2 (2020). doi:10.1016/i.cell.2020.02.058 Medline

19. Y. Yuan, D. Cao, Y. Zhang, J. Ma, J. Qi, Q. Wang, G. Lu, Y. Wu, J. Yan, Y. Shi, X. Zhang, G. F. Gao, Cryo-EM structures of MERS-CoV and SARS-CoV spike glycoproteins reveal the dynamic receptor binding domains. Nat. Commun. 8, 15092 (2017). doi:10.1038/ncomms15092 Medline

20. M. Gui, W. Song, H. Zhou, J. Xu, S. Chen, Y. Xiang, X. Wang, Cryo-electron microscopy structures of the SARS-CoV spike glycoprotein reveal a prerequisite conformational state for receptor binding. Cell Res. 27, 119-129 (2017). doi:10.1038/cr.2016.152 Medline

21. R. N. Kirchdoerfer, N. Wang, J. Pallesen, D. Wrapp, H. L. Turner, C. A. Cottrell, K. S. Corbett, B. S. Graham, J. S. McLellan, A. B. Ward, Stabilized coronavirus spikes are resistant to conformational changes induced by receptor recognition or proteolysis. Sci. Rep. 8, 15701 (2018). doi:10.1038/s41598-018-34171-7 Medline

22. Yuan et al. (19) observed $56 \%$ of the wild-type recombinant SARS-CoV S protein particle in none-"up" conformation and $44 \%$ in single-"up" conformation, while Kirchdoerfer et al. (21) found that recombinant SARS-CoV S protein, with K968P/V969P mutations in the S2 subunit to stabilize the prefusion conformation, has 58\% single-"up", 39\% in double-"up", and 3\% in triple-"up" conformations. However, it is not known whether the distribution of different configurations of $S$ proteins on virus surface is the same as that of recombinant $S$ protein.

23. S. Bangaru, S. Lang, M. Schotsaert, H. A. Vanderven, X. Zhu, N. Kose, R. Bombardi, J. A. Finn, S. J. Kent, P. Gilchuk, I. Gilchuk, H. L. Turner, A. García-Sastre, S. Li, A. B. Ward, I. A. Wilson, J. E. Crowe Jr., A site of vulnerability on the influenza virus hemagglutinin head domain trimer interface. Cell 177, 1136-1152.e18 (2019). doi:10.1016/i.cell.2019.04.011 Medline

24. A. Watanabe, K. R. McCarthy, M. Kuraoka, A. G. Schmidt, Y. Adachi, T. Onodera, K. Tonouchi, T. M. Caradonna, G. Bajic, S. Song, C. E. McGee, G. D. Sempowski, F. Feng, P. Urick, T. B. Kepler, Y. Takahashi, S. C. Harrison, G. Kelsoe, Antibodies to a conserved influenza head interface epitope protect by an IgG subtypedependent mechanism. Cell 177, 1124-1135.e16 (2019). doi:10.1016/i.cell.2019.03.048 Medline

25. G. Bajic, M. J. Maron, Y. Adachi, T. Onodera, K. R. McCarthy, C. E. McGee, G. D. Sempowski, Y. Takahashi, G. Kelsoe, M. Kuraoka, A. G. Schmidt, Influenza antigen engineering focuses immune responses to a subdominant but broadly protective viral epitope. Cell Host Microbe 25, 827-835.e6 (2019). doi:10.1016/i.chom.2019.04.003 Medline

26. J. Lee, D. R. Boutz, V. Chromikova, M. G. Joyce, C. Vollmers, K. Leung, A. P. Horton, B. J. DeKosky, C.-H. Lee, J. J. Lavinder, E. M. Murrin, C. Chrysostomou, K. H. Hoi, Y. Tsybovsky, P. V. Thomas, A. Druz, B. Zhang, Y. Zhang, L. Wang, W.-P. Kong, D. Park, L. I. Popova, C. L. Dekker, M. M. Davis, C. E. Carter, T. M. Ross, A. D. Ellington, P. C. Wilson, E. M. Marcotte, J. R. Mascola, G. C. Ippolito, F. Krammer, S. R. Quake, P. D. Kwong, G. Georgiou, Molecular-level analysis of the serum antibody repertoire in young adults before and after seasonal influenza vaccination. Nat. Med. 22, 1456-1464 (2016). doi:10.1038/nm.4224 Medline 
27. C. Dreyfus, N. S. Laursen, T. Kwaks, D. Zuijdgeest, R. Khayat, D. C. Ekiert, J. H. Lee, Z. Metlagel, M. V. Bujny, M. Jongeneelen, R. van der Vlugt, M. Lamrani, H. J. W. M. Korse, E. Geelen, Ö. Sahin, M. Sieuwerts, J. P. J. Brakenhoff, R. Vogels, O. T. W. Li, L. L. M. Poon, M. Peiris, W. Koudstaal, A. B. Ward, I. A. Wilson, J. Goudsmit, R. H. E. Friesen, Highly conserved protective epitopes on influenza B viruses. Science 337, 1343-1348 (2012). doi:10.1126/science.1222908 Medline

28. C. Petro, P. A. González, N. Cheshenko, T. Jandl, N. Khajoueinejad, A. Bénard, M. Sengupta, B. C. Herold, W. R. Jacobs Jr., Herpes simplex type 2 virus deleted in glycoprotein D protects against vaginal, skin and neural disease. eLife 4, e06054 (2015). doi:10.7554/eLife.06054 Medline

29. A. Bootz, A. Karbach, J. Spindler, B. Kropff, N. Reuter, H. Sticht, T. H. Winkler, W. J. Britt, M. Mach, Protective capacity of neutralizing and non-neutralizing antibodies against glycoprotein B of cytomegalovirus. PLOS Pathog. 13, e1006601 (2017). doi:10.1371/journal.ppat.1006601 Medline

30. C. W. Burke, J. W. Froude, S. Miethe, B. Hülseweh, M. Hust, P. J. Glass, Human-like neutralizing antibodies protect mice from aerosol exposure with western equine encephalitis virus. Viruses 10, 147 (2018). doi:10.3390/v10040147 Medline

31. E. A. Henchal, L. S. Henchal, J. J. Schlesinger, Synergistic interactions of anti-NS1 monoclonal antibodies protect passively immunized mice from lethal challenge with dengue 2 virus. J. Gen. Virol. 69, 2101-2107 (1988). doi:10.1099/0022-131769-8-2101 Medline

32. V. D. Menachery, B. L. Yount Jr., K. Debbink, S. Agnihothram, L. E. Gralinski, J. A. Plante, R. L. Graham, T. Scobey, X.-Y. Ge, E. F. Donaldson, S. H. Randell, A. Lanzavecchia, W. A. Marasco, Z.-L. Shi, R. S. Baric, A SARS-like cluster of circulating bat coronaviruses shows potential for human emergence. Nat. Med. 21, 1508-1513 (2015). doi:10.1038/nm.3985 Medline

33. V. D. Menachery, B. L. Yount Jr., A. C. Sims, K. Debbink, S. S. Agnihothram, L. E. Gralinski, R. L. Graham, T. Scobey, J. A. Plante, S. R. Royal, J. Swanstrom, T. P. Sheahan, R. J. Pickles, D. Corti, S. H. Randell, A. Lanzavecchia, W. A. Marasco, R. S. Baric, SARS-like WIV1-CoV poised for human emergence. Proc. Natl. Acad. Sci. U.S.A. 113, 3048-3053 (2016). doi:10.1073/pnas.1517719113 Medline

34. E. Krissinel, K. Henrick, Inference of macromolecular assemblies from crystalline state. J. Mol. Biol. 372, 774-797 (2007). doi:10.1016/i.jmb.2007.05.022 Medline

35. J. E. Pak, C. Sharon, M. Satkunarajah, T. C. Auperin, C. M. Cameron, D. J. Kelvin, J. Seetharaman, A. Cochrane, F. A. Plummer, J. D. Berry, J. M. Rini, Structural insights into immune recognition of the severe acute respiratory syndrome coronavirus S protein receptor binding domain. J. Mol. Biol. 388, 815-823 (2009). doi:10.1016/j.jmb.2009.03.042 Medline

36. W. C. Hwang, Y. Lin, E. Santelli, J. Sui, L. Jaroszewski, B. Stec, M. Farzan, W. A. Marasco, R. C. Liddington, Structural basis of neutralization by a human antisevere acute respiratory syndrome spike protein antibody, 80R. J. Biol. Chem. 281, 34610-34616 (2006). doi:10.1074/jbc.M603275200 Medline

37. D. C. Ekiert, R. H. E. Friesen, G. Bhabha, T. Kwaks, M. Jongeneelen, W. Yu, C. Ophorst, F. Cox, H. J. W. M. Korse, B. Brandenburg, R. Vogels, J. P. J. Brakenhoff, R. Kompier, M. H. Koldijk, L. A. H. M. Cornelissen, L. L. M. Poon, M. Peiris, W. Koudstaal, I. A. Wilson, J. Goudsmit, A highly conserved neutralizing epitope on group 2 influenza A viruses. Science 333, 843-850 (2011). doi:10.1126/science.1204839 Medline

38. A. C. Walls, X. Xiong, Y.-J. Park, M. A. Tortorici, J. Snijder, J. Quispe, E. Cameroni, R. Gopal, M. Dai, A. Lanzavecchia, M. Zambon, F. A. Rey, D. Corti, D. Veesler, Unexpected receptor functional mimicry elucidates activation of coronavirus fusion. Cell 176, 1026-1039.e15 (2019). doi:10.1016/j.cell.2018.12.028 Medline

39. Z. Otwinowski, W. Minor, Processing of X-ray diffraction data collected in oscillation mode. Methods Enzymol. 276, 307-326 (1997). doi:10.1016/S00766879(97)76066-X

40. A. Teplyakov, J. Luo, G. Obmolova, T. J. Malia, R. Sweet, R. L. Stanfield, S. Kodangattil, J. C. Almagro, G. L. Gilliland, Antibody modeling assessment II. Structures and models. Proteins 82, 1563-1582 (2014). doi:10.1002/prot.24554 Medline

41. F. Li, W. Li, M. Farzan, S. C. Harrison, Structure of SARS coronavirus spike receptor-binding domain complexed with receptor. Science 309, 1864-1868 (2005). doi:10.1126/science.1116480 Medline

42. K. Arnold, L. Bordoli, J. Kopp, T. Schwede, The SWISS-MODEL workspace: A webbased environment for protein structure homology modelling. Bioinformatics 22 , 195-201 (2006). doi:10.1093/bioinformatics/bti770 Medline
43. P. Emsley, K. Cowtan, Coot: Model-building tools for molecular graphics. Acta Crystallogr. D 60, 2126-2132 (2004). doi:10.1107/S0907444904019158 Medline 44. P. D. Adams, P. V. Afonine, G. Bunkóczi, V. B. Chen, I. W. Davis, N. Echols, J. J. Headd, L.-W. Hung, G. J. Kapral, R. W. Grosse-Kunstleve, A. J. McCoy, N. W. Moriarty, R. Oeffner, R. J. Read, D. C. Richardson, J. S. Richardson, T. C. Terwilliger, P. H. Zwart, PHENIX: A comprehensive Python-based system for macromolecular structure solution. Acta Crystallogr. D 66, 213-221 (2010). doi:10.1107/S0907444909052925 Medline

45. N. C. Wu, G. Grande, H. L. Turner, A. B. Ward, J. Xie, R. A. Lerner, I. A. Wilson, In vitro evolution of an influenza broadly neutralizing antibody is modulated by hemagglutinin receptor specificity. Nat. Commun. 8, 15371 (2017). doi:10.1038/ncomms 15371 Medline

46. W. Song, M. Gui, X. Wang, Y. Xiang, Cryo-EM structure of the SARS coronavirus spike glycoprotein in complex with its host cell receptor ACE2. PLOS Pathog. 14, e1007236 (2018). doi:10.1371/iournal.ppat.1007236 Medline

\section{ACKNOWLEDGMENTS}

We thank Henry Tien for technical support with the crystallization robot, Jeanne Matteson for contribution to mammalian cell culture, Wenli Yu to insect cell culture, Robyn Stanfield for assistance in data collection, and Andrew Ward for discussion. Funding: This work was supported by NIH K99 Al139445 (to N.C.W.), Calmette and Yersin scholarship from the Pasteur International Network Association (to H.L.), Bill and Melinda Gates Foundation OPP1170236 (to I.A.W.), Guangzhou Medical University High-level University Innovation Team Training Program (Guangzhou Medical University released [2017] No.159) (to C.K.P.M.), National Natural Science Foundation of China (NSFC)/Research Grants Council (RGC) Joint Research Scheme (N_HKU737/18) (to C.K.P.M.). GM/CA at APS has been funded in whole or in part with Federal funds from the National Cancer Institute (ACB-12002) and the National Institute of General Medical Sciences (AGM-12006). This research used resources of the Advanced Photon Source, a U.S. Department of Energy (DOE) Office of Science User Facility operated for the DOE Office of Science by Argonne National Laboratory under Contract No. DEAC02-06CH11357. Author contributions: M.Y., N.C.W., X.Z., C.K.P.M. and I.A.W. conceived and designed the study. M.Y., N.C.W. and C.C.D.L. expressed and purified the proteins. M.Y. and N.C.W. performed biolayer interferometry binding assays. R.T.Y.S., H.L. and C.K.P.M. performed the neutralization and virus binding experiments. M.Y., N.C.W. and X.Z. collected the X-ray data, determined and refined the X-ray structures. M.Y., N.C.W. and C.K.P.M. analyzed the data. M.Y., N.C.W. and I.A.W. wrote the paper and all authors reviewed and edited the paper. Competing interests: The authors declare no competing interests. Data and materials availability: $X$-ray coordinates and structure factors are deposited at the RCSB Protein Data Bank under accession code: 6 W41. This work is licensed under a Creative Commons Attribution 4.0 International (CC BY 4.0) license, which permits unrestricted use, distribution, and reproduction in any medium, provided the original work is properly cited. To view a copy of this license, visit https:/creativecommons.org/licenses/by/4.0/. This license does not apply to figures/photos/artwork or other content included in the article that is credited to a third party; obtain authorization from the rights holder before using such material.

\section{SUPPLEMENTARY MATERIALS}

science.sciencemag.org/cgi/content/full/science.abb7269/DC1

Materials and Methods

Figs. S1 to 56

Tables S1 to S3

References (37-46)

MDAR Reproducibility Checklist

14 March 2020; accepted 1 April 2020

Published online 3 April 2020

10.1126/science.abb7269 
Table 1. Binding affinity of CR3022 to recombinant RBD and S protein.

Affinity $\left(K_{d}\right.$ in $\left.n M\right) \quad$ CR3022 IgG $\quad$ CR3022 Fab

SARS-CoV-2 RBD

$<0.1$

$115 \pm 3$

SARS-CoV RBD

$<0.1$

$1.0 \pm 0.1$ 

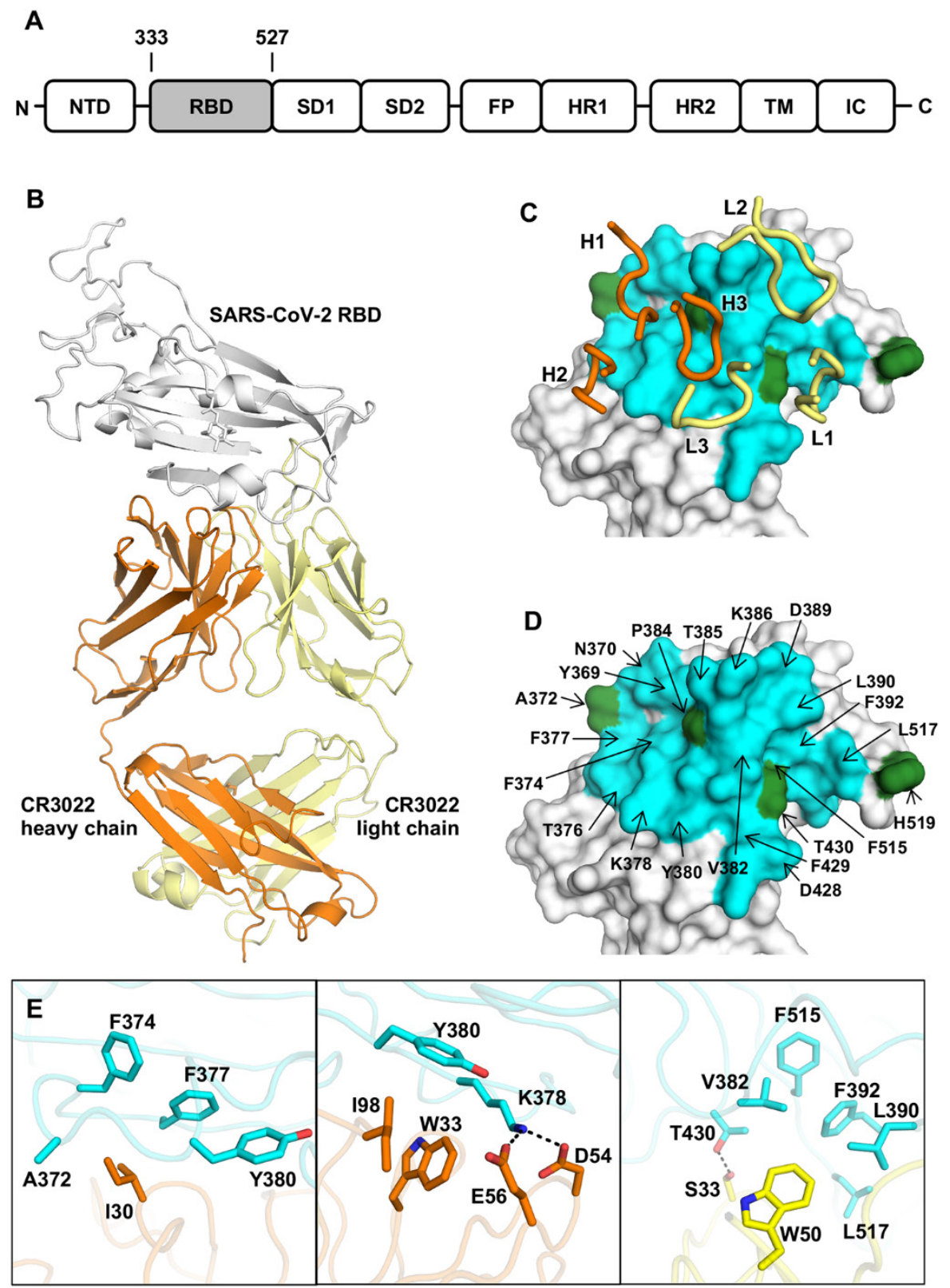

Fig. 1. Crystal structure of CR3022 in complex with SARS-CoV-2 RBD. (A) Overall topology of the SARS-CoV-2 spike glycoprotein. NTD: N-terminal domain, RBD: receptor-binding domain, SD1: subdomain 1, SD2: subdomain 2, FP: fusion peptide, HR1: heptad repeat 1, HR2: heptad repeat 2, TM: transmembrane region, IC: intracellular domain. (B) Structure of CR3022 Fab in complex with SARS-CoV-2 RBD. CR3022 heavy chain is colored in orange, CR3022 light chain in yellow, and SARS-CoV-2 RBD in light grey. (C and D) Epitope residues on SARS-CoV-2 are colored in cyan and green. CDR loops are labeled. Cyan: epitope residues that are conserved between SARS-CoV-2 and SARS-CoV. Green: epitope residues that are not conserved between SARS-CoV-2 and SARS-CoV. (D) Epitope residues that are important for binding to CR3022 are labeled. Epitope residues are defined here as residues in SARSCoV-2 RBD with buried surface area $>0 \AA^{2}$ after Fab CR3022 binding as calculated with PISA (34). (E) Several key interactions between CR3022 and SARS-CoV-2 RBD are highlighted. CR3022 heavy chain is colored in orange, CR3022 light chain in yellow, and SARS-CoV-2 RBD in cyan. Hydrogen bonds are represented by dashed lines. 
A
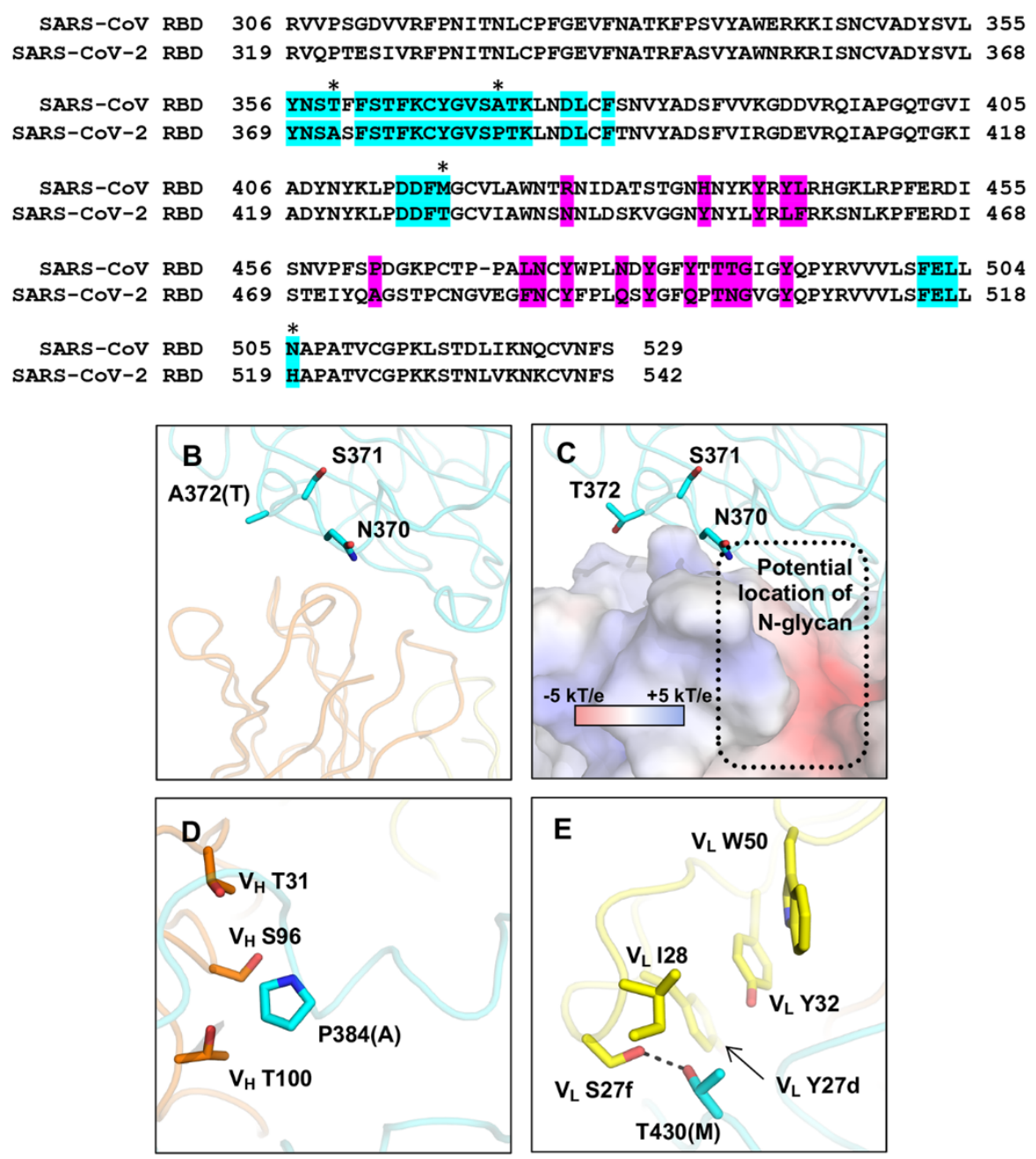

Fig. 2. Conservation of epitope residues. (A) Sequence alignment of SARS-CoV-2 RBD and SARS-CoV RBD. CR3022 epitope residues are colored cyan. ACE2-binding residues are colored magenta. Non-conserved epitope residues are marked by asterisks. (B to $\mathrm{E}$ ) Interactions between the non-conserved epitope residues and CR3022 are shown. Amino-acid variants observed in SARS-CoV are in parenthesis. SARS-CoV-2 RBD is colored in cyan, CR3022 heavy chain in orange, and CR3022 light chain in yellow. Residues are numbered according to their positions on the SARSCoV-2 S protein sequence. (B) While SARS-CoV-2 has an Ala at residue 372, SARS-CoV has a Thr, which introduces an N-glycosylation site at residue N370. (C) The potential location of N370 glycan in SARS-CoV RBD is indicated by the box. CR3022 is shown as an electrostatic potential surface presentation. (D) P384 interacts with T31, S96, and T100 of CR3022 heavy chain. Ala at this position in SARS-CoV would allow the backbone to adopt a different conformation when binding to CR3022. (E) T430 forms a hydrogen bond with S27f of CR3022 light chain. Met at this position in SARS-CoV would instead likely insert its side chain into the hydrophobic pocket formed by Y27d, 128, Y32, and W50 of CR3022 light chain. 
A
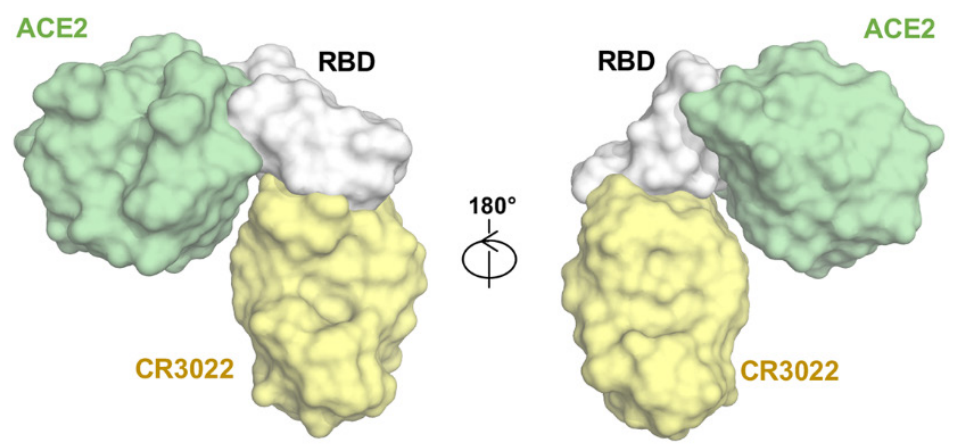

B
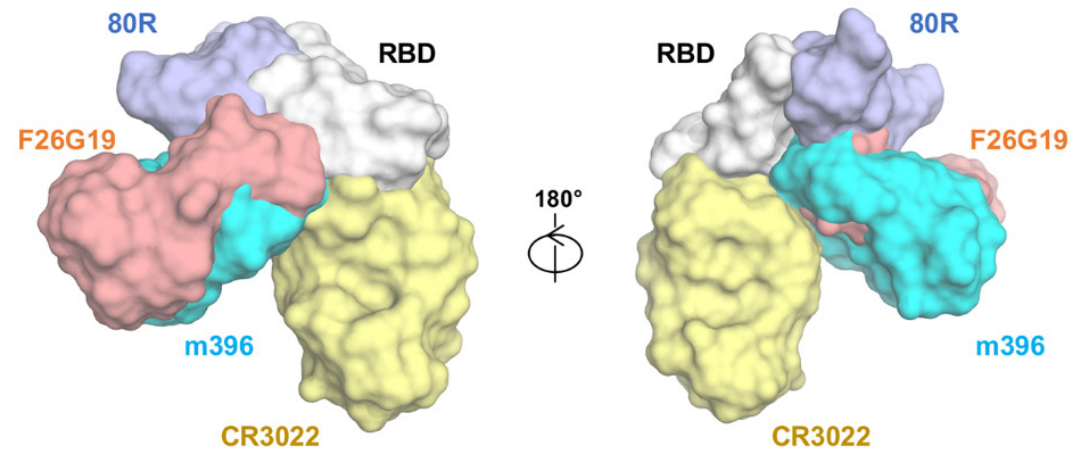

Fig. 3. The relative binding location of CR3022 with respect to receptor ACE2 and other SARS-CoV RBD monoclonal antibodies. (A) Structures of CR3022-SARS-CoV-2 RBD complex and ACE2-SARSCoV-2 RBD complex (11) are aligned based on the SARS-CoV-2 RBD. ACE2 is colored in green, RBD in light grey, and CR3022 in yellow. (B) Structural superposition of CR3022-SARS-CoV-2 RBD complex, F26G19-SARS-CoV RBD complex (PDB 3BGF) (35), 80R-SARS-CoV RBD complex (PDB 2GHW) (36), and m396-SARS-CoV RBD complex (PDB 2DD8) (16). 

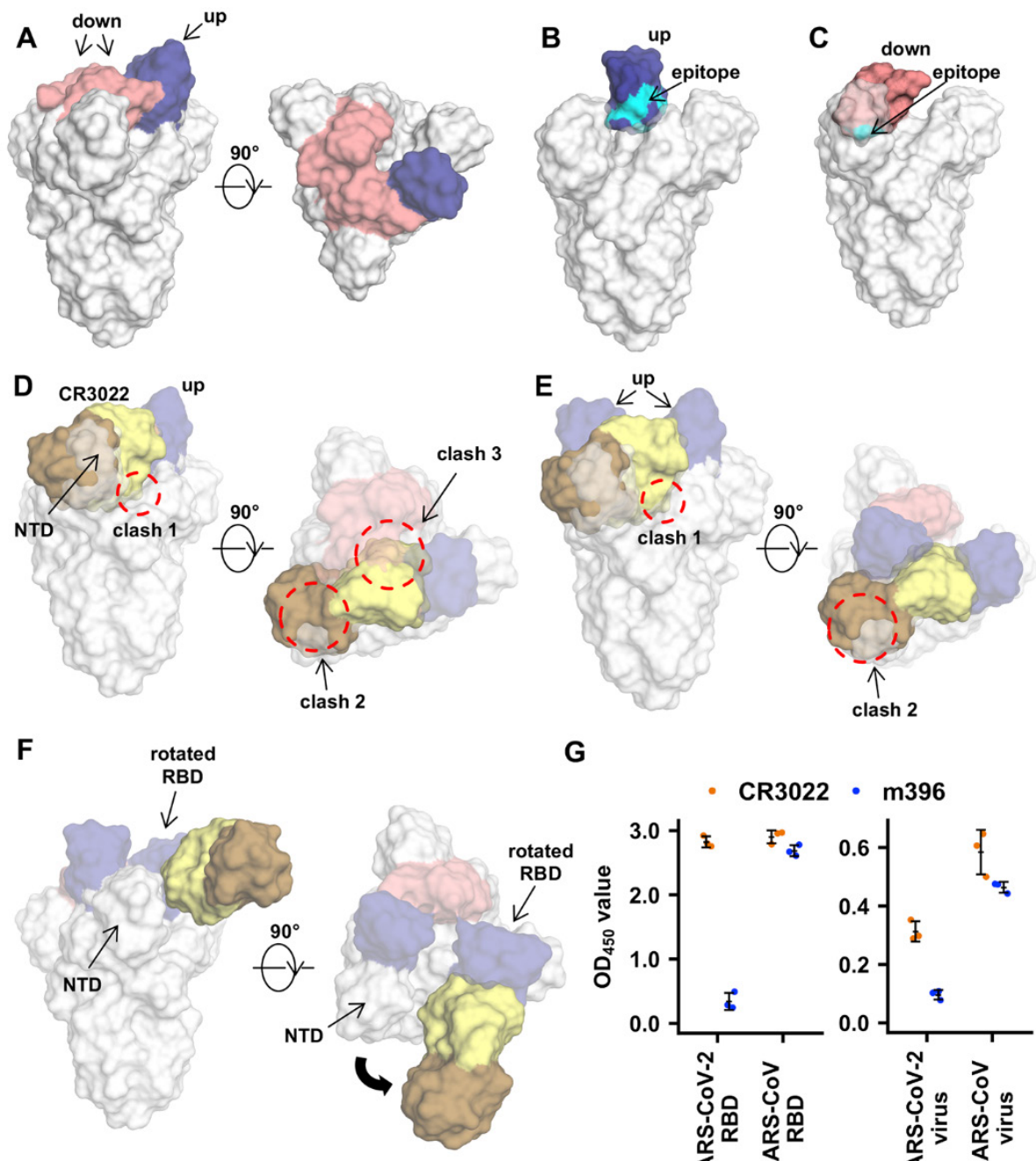

G

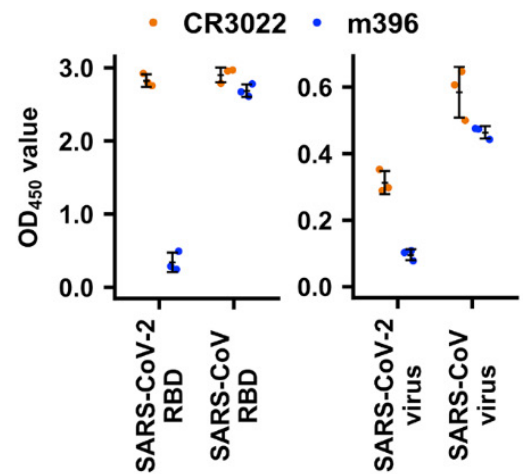

Fig. 4. Model of the binding of CR3022 to the homotrimeric S protein. (A) RBD in the S proteins of SARS-CoV-2 and SARS-CoV can adopt either an "up" conformation (blue) or a "down" conformation (red). PDB 6VSB (cryo-EM structure of SARS-CoV-2 S protein) (17) is shown. (B and C) CR3022 epitope (cyan) on the RBD is exposed in (B) the "up" but not (C) the "down" conformation. (D) Binding of CR3022 to single-"up" configuration would clash (indicated by the red circles) with the S protein. Clash 1: CR3022 variable region clashes with the S2 subunit. Clash 2: CR3022 constant region clashes with NTD. Clash 3: CR3022 variable region clashes with the neighboring RBD that is in "down" conformation. CR3022 variable region is colored yellow. CR3022 constant region is colored brown. (E) Clash 3 can be resolved when the neighboring RBD is in "up" conformation (i.e., S protein in double-"up" configuration). (F) All clashes can be resolved if the targeted RBD is slightly rotated in the double-"up" configuration. The curved arrow indicates the change in CR3022 orientation due to the slight rotation of the RBD. Of note, given the elbow angle between the constant and variable domains of CR3022 is the same as observed in our crystal structure, our model shows a maximum rotation angle of around $45^{\circ}$ for the RBD would avoid all clashes. However, the elbow region of an antibody is known to be highly flexible. Therefore, the rotation angle of the RBD could be much smaller when the spike trimer is bound to CR3022. (G) Binding of CR3022 IgG and m396 IgG to recombinant RBD proteins from SARS-CoV-2 and SARS-CoV (left panel), as well as SARS-CoV-2 and SARS-CoV viruses (right panel). Black lines indicate mean $+/-$ standard deviation of three technical replicates. 